\title{
EL PERFECTO CUENTISTA: \\ COMENTARIO A TRES TEXTOS DE HORACIO QUIROGA
}

\author{
POR \\ ROBERTO PAOLI \\ Università di Firenze
}

\section{"A LA DERIVA"}

Este cuento en tercera persona, ${ }^{1}$ con narrador externo a la historia, enfoca ese lapso de tiempo, épico o novelístico, que transcurre entre el momento en que el personaje recibe una herida mortal y el momento de la muerte real. El hombre, cuya lucha con la muerte se relata aquí, se llama Paulino- el nombre nos es revelado incidentalmente durante una microsecuencia dialogística (8$10),{ }^{2}$ pero, si se prescinde de este punto de poco relieve, siempre es llamado "el hombre" (eso ocurre quince veces, seis al principio del párrafo: un buen número para un cuento tan breve), como si se quisiera evidenciar:

a) el anonimato: no es un individuo cuyo nombre importe, sino uno como hay tantos, un pobre peón de una región remota del mundo;

b) la especie humana: es el hombre, cualquier hombre, quien, sentenciado a muerte (pena capital, enfermedad, accidente), no se resigna a morir y lucha hasta lo último para sobrevivir. Hay quien se rinde, pero es la excepción, no la regla, pues, por regla general, la conducta del hombre en tan mal trance no es sufrir pasivamente el destino, sino, al contrario, acelerar el ritmo de su vida a fin de ganar la carrera con la muerte.

Vicisitudes de hombres heridos de muerte, que utilizan lo que les queda de fuerzas para arrastrarse hasta adonde puedan curarlos, o bien hombres amenazados de muerte, acosados, acorralados, que a veces son alcanzados y matados, y otras consiguen salvarse, o bien de gente fugitiva que escapa de una catástrofe (peste, incendio, inundación, terremoto, etc.), constituyen un tema épico dramático presente en la literatura narrativa, y aún más en la cinematografía, pues, debiéndose representar una carrera afanosa, los medios

\footnotetext{
${ }^{1}$ Se publicó primero en Fray Mocho (7-VI-1912) y se recogió luego en Cuentos de amor, de locura y de muerte (1917).

${ }^{2}$ Los números arábigos entre paréntesis se refieren siempre a los párrafos. Para la numeración progresiva de los párrafos se consideran todos los "puntos y aparte", incluso cuando separan sólo breves intervenciones dialogísticas.
} 
del cine resultan lo más idóneos. Pero hay otro caso más, aunque menos frecuente: es el del hombre solo, que, herido o enfermo mortalmente, no está en condiciones de desplazarse del lugar en que lo ha alcanzado la desgracia, y no puede hacer otra cosa que un viaje mental, en cuyo trayecto lo acompaña el pensamiento de la muerte inminente (a esta última tipología pertenece el episodio de la muerte de Don Rodrigo, que Manzoni narra, sirviéndose en parte de un espasmódico presente, en el capítulo XXXIII de Los novios).

En este cuento de Quiroga se observa, primeramente, que el punto de vista dominante no es externo al hombre que está a punto de morir, sino interno. Se trata, pues, de una narración de focalización interna, ${ }^{3}$ en la que el narrador muestra no saber más que el personaje y relata la desesperada lucha de éste con la muerte desde la perspectiva del moribundo. Es verdad que los tres primeros párrafos pueden definirse como behavioristas, es decir, de focalización externa, si se exceptúa la frase "Un dolor agudo nacía ..." (3), ya que es el personaje quien siente el dolor y el narrador externo puede sólo inferirlo de los gestos del personaje. Pero la focalización interna se insinúa en el cuarto párrafo y llega a ser progresivamente dominante, aun no excluyendo enunciados de focalización que puede ser externa, además de interna. La serie de focalizaciones presentes en este relato es la siguiente: 1) externa; 2) interna (sobre la sensación física); 3) interna (sobre la conciencia). No se registra, sin embargo, una progresión propiamente geométrica de la focalización interna, o sea que la tripartición no corresponde exactamente a una sucesión de tres fases homogéneas, si bien es verdad que esas tres perspectivas aparecen en el cuento en el orden en que las hemos enumerado. La tercera es dominante en la última parte del relato, cuando, siendo ya próxima la muerte del personaje, el dolor físico se alivia a causa del coma que está por llegar, y deja lugar al recuerdo y al delirio. En esta parte final la focalización interna prevalece, a tal punto que se aproxima a veces a las modalidades del monólogo interior: "¿Viviría aún su compadre Gaona, en Tacurú-Pucú? ...”(22); “¿Llegaría pronto?..” (23); “¿Tres años? Tal vez no, no tanto ...” (245).

Según nuestra formalización, el relato "A la deriva” puede segmentarse en tres secuencias.

La primera abarca los párrafos I-18, hasta "...la llevó velozmente a la deriva", es decir, comprende toda la serie de eventos y acciones desde que el hombre recibe la mordedura de la serpiente hasta que se abandona a la corriente del río; la serpiente lo muerde; él se venda la herida con el pañuelo; corre a su casa; bebe aguardiente; se embarca en su canoa; pide socorro a su compadre Alves, pero el compadre no está (o no quiere responder); vuelve a arrastrarse hasta su canoa, que es llevada a la deriva por la corriente. La unidad del trozo consiste en que la focalización externa prevalece sobre la interna y las acciones

${ }^{3}$ Nos ajustamos fundamentalmente a la sistematización conceptual y terminologica de Gérard Genette, Figures III (París: Seuil, 1972). 
prevalecen sobre los pensamientos. Motiva y acompaña a tales acciones el dolor de la mordedura, que en el curso de la secuencia se hace cada vez mayor. Hay, pues, un proceso ascensional de la agitación y del dolor que alcanza su máxima intensidad al final de la secuencia.

EL segundo segmento, que tiene también una función de entronque entre el primero y el tercero, comprende sólo el párrafo 19: "El Paraná corre alli ...". Se trata de un párrafo completamente descriptivo, pero no debe creerse que su focalización sea externa. Todo lo que el narrador dice del Paraná lo sabe también el personaje, no sólo porque es un conocedor de estos parajes, sino porque, ante todo, proyecta sobre el paisaje sus presagios fúnebres. El personaje, por cierto no sabría expresar con palabras la sugestión sombría, agresiva y majestuosa que el gran río despierta hasta en los nativos, y no sería capaz de formular su sentimiento del paisaje por medio del enunciado: "El paisaje es agresivo y reina en él un silencio de muerte" (19), que es una manera de enunciar propia del narrador. Sin embargo, aunque no sabe expresarlo, el personaje advierte esa agresividad, esa belleza sombría, esa majestad..

Pero, ¿por qué no las advirtió hasta ahora? Es evidente. En el primer segmento la conciencia del hombre está totalmente embargada por la herida y por la voluntad de salvarse: por consiguiente, el paisaje nunca está descrito directamente, sino tan sólo sugerido por ciertos nombres (yara cacusú, machete, trapiche, etc.). Ahora, en cambio, la conciencia se deja ya llevar ella misma a la deriva, volviendo a abrirse - primero angustiosamente, luego casi con una nueva esperanza - al contorno espacial. El dolor ha alcanzado su mayor intensidad y la esperanza inicial se ha frustrado, por faltarle la ayuda del compadre Alves, quien está ausente o se niega a socorrerlo. Es digno de atención el hecho que el narrador no precise si el compadre está lejos o si no quiere acudir. Tal indeterminación está acorde con la focalización que el narrador ha escogido, porque, si nos hubiese hecho saber la verdadera razón por la cual el hombre no recibe ayuda, se habría convertido en un narrador que sabe más que el personaje. Pero, de acuerdo con la regla de la focalización interna, el narrador no debe saber más que el personaje, el cual, en este caso, sólo sabe que Alves no responde.

Este párrafo descriptivo, paisajístico ("El Paraná corre allí ...", 19) es angustioso, pero no dramático, y representa bien la mutación entre el drama del hombre y la serenidad de la muerte, anunciada por el entorpecimiento que la precede. Es un verdadero momento de necesaria mutación - psicológica, rítmica, musical-entre el primer segmento(agitado, espasmódico, atormentado, pues es la vida que agoniza, que forcejea, que no quiere morir, mientras la gangrena crece hasta un punto irreversible) y el tercer segmento, que desarrolla el motivo con que termina textualmente el primero: "a la deriva". Esta secuencia es, en efecto, más sosegada y relajada, aunque también concisa y veloz, dominada por un aparente "bienestar" o sea, por una sensación engañosa, que saca a la superficie de la memoria del moribundo algún recuerdo que se 
convierte en esperanza: una ayuda humana que todavía puede llegarle de su antiguo patrón, después de la fallida, o no prestada, por su mujer y su compadre.

El tercer segmento comienza con las palabras "El sol había caído ya ..." y termina con el final del cuento (párrafos 20-30). Hay en él otro ritmo, que forma contraste con el ritmo tenso y espasmódico del primer segmento, sin faltar a la regla de la esencial economía de medios que se usa en el relato. El cambio de ritmo y tonalidad se debe exactamente al cambio de tiempo, es decir, a la preponderancia-ahora- de imperfectos y, en menor medida, de pluscuamperfectos sobre los pretéritos indefinidos. El imperfecto es el tiempo del continuum, de la demora, del estancamiento: connota una permanencia en el tiempo, casi una contemplación de la memoria. La breve oración "se sentía mejor" $(20)$ quiere significar que se trata de una sensación no momentánea, sino prolongada. Los enunciados " $\mathrm{El}$ cielo, al poniente, se abría ahora en pantalla de oro ..."(23) y "el monte dejaba caer ..." (ibid.) se refieren a un tiempo que puede ser cronométricamente breve y que, sin embargo, es también largo y casi eterno, porque invita a la dilación contemplativa, deja una estela en la mente, $\mathrm{y}$, al esfumarse en momentos atmosféricos diversos, lo hace por medio de imperceptibles mutaciones.

Como afirma Charles Bally, el imperfecto insiste en la duración o en la repetición, en tanto que el pretérito indefinido ásla el hecho en el pasado y condensa la duración en un punto. ${ }^{4}$ Por tanto, la sucesión rápida de pretéritos indefinidos da la sensación de un movimiento, de una serie apremiante de acciones o acontecimientos, que es precisamente lo que se representa en la primera secuencia. Las acciones épicas o dramáticas están narradas, por lo general, en pretérito indefinido, el cual puede alternar, sin embargo, con el presente histórico (la alternancia determina efectos de ritmo) o bien sustituirse totalmente con el mismo presente. Si se lee el ya citado episodio de la muerte de Don Rodrigo (capítulo XXXIII de Los novios ), se observa que está narrado en los varios tiempos pretéritos, a excepción de un trozo de más suspenso que se narra en presente:

De pronto oye un tintineo lejano, pero que le parece venir de las habitaciones, no de la calle. Presta atención; lo oye más fuerte, más repetido, y a la vez un arrastrar de pies: una horrible sospecha pasa por su mente. Se sienta en la cama, y escucha con mayor atención; oye un ruido sordo en la habitación de al lado, como de un peso depositado en el suelo con sigilo; saca las piemas de la cama, como para levantarse, mira a la puerta, la ve abrirse, y ve aparecer y adelantarse dos raídos y sucios trajes rojos, dos rostros de herejes, dos monatos, en una palabra.

"Lingüistique Générale et lingüistique française (Berne: Francke Verlag, 1950), 585.

- Alessandro Manzoni, Los novios, edición y traducción de Ma. Nieves Muñiz (Madrid: Ediciones Cátedra, 1985), 633. 
Lo mismo ocurre al principio del IV capítulo de Hijo de hombre de Augusto Roa Bastos, donde el momento más agitado de la fuga de Casiano Jara y de su mujer ha sugerido al narrador un desenvolvimiento en tiempo presente:

Avanzan despacio en la maciega del monte. Más rápido no pueden. Empujados por el apuro, por el miedo ya puramente animal, se cuelan a empujones. Por momentos, cuando más ciegas son las embestidas, la maraña los rebota hacia atrás. Entonces el impulso de la desesperación se adelanta, se va más lejos, los abandona casi. El hombre machetea rabiosamente para recuperarlo....6

Volveremos a encontrar la alternancia de pretéritos y presente en el cuento "El hombre muerto", en tanto que "El hijo", último ejemplo de nuestra serie, está totalmente narrado en tiempo presente.

El tercer segmento emplea predominantemente el pretérito imperfecto, y configura una situación de evolución más lenta, en la que el personaje se mueve y piensa con torpeza: el discurso está caracterizado por las dudas, por los pensamientos que se repiten circular y obsesivamente (el ex-patrón y el recibidor del obraje vuelven dos veces a la memoria del moribundo), lo cual no impide que la secuencia tenga su crescendo. Mientras en la primera lo que crece son el dolor físico y la desesperación, vemos en ésta un crecimiento en sentido opuesto, o sea, un decrecimiento del dolor (o un decrescendo, si se prefiere la metáfora musical), el progresivo retorno a una sensación de bienestar: "se sentía mejor"(20); "se hallaba casi bien"(21): "No sentía ya nada ni en la pierna ni en el vientre" (22); "Se sentía cada vez mejor"(24). Concomitante es el fenómeno de la dilatación de la esperanza: "contaba con la caída del rocío para reponerse del todo" (21); "calculó que antes de tres horas estaría en Tacuru-Pucú" (ibid.); "el cielo se abría en pantalla de oro"(23). Después de esta progresión, notamos, ya a pocos renglones del término del cuento ("De pronto sintió que...", 25), un rápido precipitarse de los sucesos hacia su fin trágico: tres momentos escuetos, en que se abandona el imperfecto y se vuelve al pretérito indefinido, ya que se trata de una sucesión precipitada de hechos que se subsiguen con intervalos más breves: "De pronto sintió..." (25); "El hombre estiró..." (28); "Y cesó de respirar" (30). Y no se deja de observar - para ver cuán calculado está el decrescendola disminución progresiva de los intervalos entre los tres pretéritos indefinidos.

Esta tercera secuencia está penetrada de un sentimiento contemplativo debido, no sólo a la diversa condición del personaje, sino también a la índole de su viaje, ya que el hombre va a la deriva estando inmóvil; en el fondo de la canoa. Ese sentimiento contemplativo, según hemos visto, debía estar ausente en la primera parte, porque allí toda la narración se centraba en el agravamiento de la herida, y el paisaje era invisible, si bien aludido por medio de términos aislados como machete, rancho, trapiche, costa, canoa, etc. En la parte de enlace

${ }^{6}$ Augusto Roa Bastos, Hijo de hombre (Buenos Aires: Editorial Losada, 1960), 78. 
(párrafo 19) el personaje está inmóvil en la canoa a la deriva, y la herida ha cobrado ya proporciones irreversibles. El hombre ya no tiene esperanzas y piensa en la muerte, proyectando sus pensamientos lúgubres sobre el paisaje ("Unainmensa hoya", "encajonar", "fúnebremente", "silencio de muerte"). Todo el párrafo es negro, teñido del color de los pensamientos del moribundo. Finalmente, en la tercera parte, en esa suerte de entorpecimiento general, de modorra y semiconciencia que se apodera del hombre, ocurre la metamorfosis del río, consecuencia de la cesación del dolor y del retorno de la esperanza. El paisaje, antes fúnebre, se tiñe ahora de espléndidos colores: "El cielo, al poniente, se abría ahora en pantalla de oro, y el río se había coloreado también" (23). El mismo lúgubre río, hecho de agua fangosa y sombría, se ha convertido en "un río de oro" (24). Sobre el río cae una "frescura crepuscular en penetrante efluvio" (23), y se dejan ver hasta los guacamayos (ibid.) que son papagayos de vistosos colores. El paisaje muestra ser de veras un estado de ánimo.

El mérito del arte de contar de Horacio Quiroga estriba en que el escritor logra comunicar tantas cosas con una economía de medios tan grande. Pero es, precisamente, esta economía de la palabra, este non quid nimis, esta adherencia a la esencial verdad humana de los hechos, el secreto de tal manera de contar. El escritor, que también era hombre de pocas palabras, ${ }^{7}$ no se distrae ni un instante de la línea maestra del relato. No está tentado de decirnos algo acerca de las serpientes del Paraguay, del preciso trabajo que ejecuta el peón protagonista, del género de vida de una familia de estas regiones, de la dureza del trato con los hombres, del peligro mortal representado por la naturaleza. Pero no se necesita comentario alguno, pues todo eso está sugerido por medio de alusiones, indirectamente, poéticamente.

El cuento se delimita para concentrarse en un hombre, mejor dicho, en "el hombre", y en la circunstancia que le es fatal. Nos habla de la naturaleza sólo lo necesario para sugerirnos el papel esencial e ineludible que ella tiene en la aventura del hombre en estos parajes. Ni le dan tentaciones - repito- de justificar la conducta de la esposa del hombre (antes, o después, del breve, rudo, dramático diálogo con ella, 5-10), ni de explicar las causas de su enemistad hacia el compadre Alves (por otro lado conjeturables, pues se trata de causas elementales) siempre que sea verdad que el compadre Alves ha oído el grito del compañero y no ha querido prestarle ayuda. Y también las épocas pasadas en que el peón trabajaba para el ex-patrón Dougald junto con otros compañeros se introducen en la narración con extremada economía, sólo en la medida en que son funcionales para revelarnos cómo trabaja la conciencia de este moribundo y, juntamente, para hacernos columbrar el duro trabajo de leñador que está a las espaldas de este hombre que sufre una muerte tan cruel. El laconismo del

\footnotetext{
${ }^{7}$ Para la semblanza humana, ver especialmente: Ezequiel Martínez Estrada, El hermano Quiroga (Montevideo: Instituto Nacional de Investigaciones, 1957); Emir Rodríguez Monegal, El desterrado, Vida y obra de Horacio Quiroga (Buenos Aires: Editorial Losada, 1968).
} 
narrador confiere al cuento un especial vigor alusivo. No importa que se omitan ciertos detalles que parecen esenciales. Al contrario, tanto el pasado del hombre, muy vago pero al mismo tiempo conjeturable, como los personajes de segundo plano, fugazmente aludidos, están dejados deliberadamente al margen para recalcar la soledad irremediable del protagonista, y hacer que el lector se fije, como se fija el personaje, en un presente tan terrible que borra cualquier otro tiempo: el presente supremo de la vida, el momento en que el hombre está solo, enfrentándose con su propia muerte.

\section{"EL HOMBRE MUERTO"}

También en este relato, ${ }^{8}$ como en el anterior, se obedece a la regla de la esencialidad narrativa y de la enconomía verbal, que es uno de los mandamientos básicos del Decálogo del perfecto cuentista, breve texto en que Quiroga ha compendiado su experiencia y su teoría del cuento. ${ }^{9}$ El séptimo precepto se refiere a la sobriedad verbal:

No adjetives sin necesidad., inútiles serán cuantas colas de color adhieras a un sustantivo débil. Si hallas que es preciso, él sólo tendrá un color incomparable. Pero hay que hallarlo.

El octavo, en cambio, se relaciona con el aspecto propiamente narrativo:

Toma a tus personajes de la mano y llévalos firmemente hasta el final, sin ver otra cosa que el camino que les trazaste. No te distraigas viendo tú lo que ellos no pueden o no les importa ver. No abuses del lector. Un cuento es una novela depurada de ripios. Ten esto por verdad absoluta, aunque no lo sea.

En efecto, también en la realización práctica de ese código, por lo menos en sus cuentos mejores, Quiroga evita las digresiones, los detenimientos discursivos demasiadolargos, los preámbulos demasiado pormenorizados. Prefiere, además, la focalización interna (en la que el narrador no ve nada más que el personaje) a la focalización cero (narrador omnisciente).

Tales preceptos valen también para "El hombre muerto", aunque son acaso menos evidentes que en "A la deriva", a causa del procedimiento extremadamente iterativo del discurso, que es el medio de índole retórico que el narrador emplea para comunicar la situación del protagonista (una vez más, un hombre está a punto de morir). El hombre, herido accidentalmente por el machete, sabe que va a morir, pero se resiste mentalmente a la horrible certidumbre. El relato recalca esta resistencia interior a aceptar una muerte tan próxima como

${ }^{8}$ Se publić́ primero en La Nación (27-VI-1920) y luego se recogio en Los desterrados (1926).

${ }^{\circledR}$ Apareció primero en Babel, 24 (1927). Se recogió póstumamente en Los perseguidos y otros cuentos (Montevideo: Biblioteca Rodo, 1940). 
inesperada e imprevista. El que va a morir no puede admitir que su existencia haya llegado al fin en un mundo que sigue su curso imperturbable. Lo absurdo es precisamente esto: la muerte individual es un suceso que rompe la relación del individuo con el mundo sin desconcertar al mundo. Si se tratase de una catástrofe general, todo sería quizás más fácil de comprender; pero la muerte del individuo es una catástrofe que sólo lo arrastra a él, en medio de un universo cuyo orden absolutamente inalterado, continúa indiferente. Ahora bien, es sobre todo por medio de iteraciones que Quiroga comunica verbalmente al lector esta resistencia a creer, esta no aceptación del acontecimiento fatal por el moribundo inmóvil e impotente, este pasmo angustioso frente a un suceso imprevisto que para el hombre es todo, y para el universo es nada. Veamos algunos ejemplos:

$\rightarrow$ Se está muriendo. Muerto. Puede considerarse muerto ...(7-8).

-fría, matemática e inexorablemente ...(4);Fría, fatal e ineludiblemente...(10).

- ¿Qué tiempo...? ¿Qué cataclismo?...¿Qué trastorno...? (9).

- Va a morir ...Va a morir...(10)

- ¿Qué ha cambiado? Nada, nada ha cambiado (16).

-El hombre resiste (II); el hombre ... se resiste (17).

- ¿Pero es posible? ¿No es este uno de los tantos días ...?(13); ¿Qué pasa entonces? Es ése o no un natural mediodía de los tantos en Misiones?(15); ¡Pero es uno de los tantos días, trivial como todos..!"(22).

- sabe muy bien ...(12); Lo sabe perfectamente bien ..."(14); Sabe bien la hora ....(17); ...él sabe muy bien ... (18); sabe que no se atreve ...(19).

La iteración sirve también para producir el efecto del gradual extinguirse de la vida de este hombre: un apagarse oculto bajo la sensación engañosa y consoladora del cansancio (la cual corresponde al bienestar que experimenta, poco antes de morirse, el hombre de "A la deriva").

-El hombre, muy fatigado ... (17).

-Está solamente fatigado, ... y descansa un rato(18).

- Muy fatigado, pero descansa sólo.

-Muy cansado, mucho, pero nada más (23).

-Descansando porque está muy cansado ..."(24).

-... que ya ha descansadon(25)

Otro factor que concurre a dar la sensación de inmovilidad y, juntamente, de angustiosa carrera con el tiempo, es la crónica de los últimos momentos del hombre, tan minuciosa y casi cronométrica:

-No han pasado dos segundos (7).

- ¿Qué tiempo ha pasado?(9).

-pronto deben ser las doce (11). 
-Desde hace dos minutos..(16).

-Hace dos minutos (16).

-Sabe bien la hora: las once y media..(17).

-Deben de haber pasado ya varios minutos..(20).

-Ya es la hora (21).

-a mediodía como ahora ...(23).

La minuciosa cadencia temporal marcha paralela con la concentración visual del personaje, con la precisión aritmética y geométrica de sus referencias a la realidad externa, con su conciencia que se ha objetivado, que se ha convertido en espacio: un espacio breve, conocido, dominado, casi medido metro por metro, que el hombre, sin embargo, ya no puede alcanzar, pues ya no le pertenece. Hágase caso a la frecuencia de verbos de la mirada (mirar, ver, entrever, echar una mirada), a más de las siguientes indicaciones espaciales:

- el sol está exactamente a la misma altura, las sombras no han avanzado un milímetro (7)

- A la izquierda (12).

- a cuatro metros de él (13).

- hay unos quince metros largos (14).

- entre su mano izquierda y el alambre de púa (18).

- panes de tierra distantes un metro uno de otro (19).

Recurramos, ahora, al procedimiento segmentativo, tendiente a evidenciar una serie de secuencias unitarias, cada cual caracterizada por una peculiaridad narrativa que la distinga de las demás. ${ }^{10}$ El reconocimiento de algunas peculiaridades narrativas y de su variación a lo largo del cuento nos permite dividir el mismo en cuatro segmentos, que primero nos limitamos a señalar y luego describiremos:

I. Párrafos 1-4.

II. Párrafos 5-6.

III. La mayor parte del cuento que abarca los párrafos 7-24.

IV. Párrafo 25.

La cesura entre una secuencia y otra se verifica cuando al menos uno de sus elementos caracterizantes sufre un cambio. Sobre el fundamento de este criterio, que no se separa esencialmente del concepto de secuencia establecido por Barthes en la Introducción citada en la nota 10 ("La secuencia se abre

\footnotetext{
10 Para la sintaxis funcional del cuento, remitimos a Roland Barthes, "Introduction $\grave{a}$ l'Analyse structurale des récits"(1966), Poétique du Récit (Paris: Seuil, 1977), y a Cesare Segre, Le strutture e il tempo (Torino: Einaudi, 1974), 24-33, aunque teoría y aplicaciones constituyen ya un capítulo rico y esencial del análisis literario contemporáneo. Para la segmentación temporal, sigue siendo básico Gérard Genette, op. cit., cap. "Ordre”.
} 
cuando uno de sus términos no tiene antecedentes solidarios y se cierra cuando otro de sus términos no tiene ya subsiguientes"), distinguimos en el cuento cuatro unidades o núcleos, cuyos límites están indicados en el esquema anterior.

I. Narración en pretérito. Focalización interna: punto de vista del que va a morir.

II. Reflexión y descripción. Pausa narrativa, Focalización cero.

III. Narración en presente. Focalización interna: punto de vista del que va a morir.

IV. Narración en presente. Focalización interna: punto de vista del caballo.

En el primer núcleo los rasgos peculiares son, pues, los siguientes:

a) el suceso está narrado en pretérito (indefinido e imperfecto);

b) el suceso está narrado desde la perspectivà del personaje que lo sufre, o sea que el narrador simula saber lo mismo que el personaje (focalización interna).

La narración presta atención a cada detalle del movimiento del personaje, pues se debe a un banal traspié que un gesto rutinario se convierte de improviso en tragedia. Ya dijimos, a propósito del cuento anterior, que se emplea normalmente el imperfecto para comunicar la duración, en tanto que el pretérito indefinido nos transmite la momentaneidad del gesto o del suceso. En efecto, los imperfectos de las oraciones principales indican preferiblemente la inmovilidad (acababa, 4 veces; estaba, dos veces; surgían); al contrario, los pretéritos indefinidos sirven para los movimientos, las sensaciones súbitas, los estados de conciencia rápidos (echóuna mirada, dos veces; cruzó, resbaló, intentó, apreció mentalmente; adquirió). Los dos tiempos concurren a formar un ritmo y una medida de normalidad narrativa. Afirma Barthes que:

el pasado narrativo forma parte ... de un sistema de seguridad de las Bellas Letras. Imagen de un orden, él constituye uno de esos numerosos contratos formales establecidos entre el escritory la sociedad, para la justificación del uno y la serenidad de la otra. ${ }^{11}$

En resumidas cuentas, es muy posible que se haya dirigido contra la escritura burguesa dominante, llena de falsedad y jactancia, la experimentación literaria de los últimos cincuenta o sesenta años, que ha tratado de desestabilizar el pretérito indefinido, la tercera persona (recurriendo incluso a la segunda, como hizo Michel Butor en La modificación), y todo lo que en la escritura tradicional era señal de una visión del mundo ya no compartida. Sin embargo, la escritura de Quiroga no es ni experimental ni burguesa: al contrario, es abiertamente tradicional, deliberadamente pobre y sin adornos. Se dirige a un

11 Roland Barthes, Le Degré zéro de l'écriture (Paris: Seuil, 1953). 
vasto público, que detesta tanto las rupturas violentas como las vanidades formales, y exige, en cambio, que la ficción logre implicarlo por medio de una ágil eficacia verbal.

En esta primera secuencia es de notar, en particular, la coordinación que se ha instaurado entre el hombre y su instrumento inanimado. El narrador no dice que "el hombre con su machete acababa de limpiar", sino que "el hombre y su machete acababan de limpiar"(I), sugiriendo que el hombre no está solo en este duro trabajo, sinoque está acompañado de otro ser animado. La coordinación equiparante entre el hombre y su machete continúa también en las frases sucesivas: Faltábanles, tenían. Por tal motivo, percibimos el machete como una presencia humana que va al lado del hombre. Este acompañamiento, empero, es ambiguo, falsamente subalterno, pues el compañero puede eludir la vigilancia del hombre, acometerlo de improviso, matarlo. El hombre estaba destinado a crearse en la soledad una ficción de compañía, pero eso le ha hecho olvidar que el machete es también un arma, potencialmente peligrosa, como todas las armas. Es precisamente esa confianza que le tiene al machete-compañero, y que ha surgido de la arraigada costumbre de trabajar juntos ("Tras diez años de bosque, él sabe muy bien cómo se maneja un machete de monte”, 18 ), lo que lo traiciona, llevándolo a cometer el fatal error de no desembarazarse del alevoso ayudante antes de saltar el alambrado.

Segundo núcleo. Los rasgos característicos de los dos párrafos que lo constituyen son:

a) la creación de una pausa discursiva, narrativamente improgresiva, que sirve de comentario a lo narrado en el primer núcleo;

b) tal comentario ya no está enunciado por un narrador, cuyo punto de vista se identifica con el del personaje, sino por un omnisciente, que introduce en el discurso consideraciones de carácter filos6fico que el personaje no estaría en condición de concebir ni de formular (por lo menos en ese trance, y con esa lucidez), aunque -oscuramente- podría intuir esas verdades y compartirlas.

La pausa discursiva funciona de enlace entre dos unidades narrativas (la primera y la tercera), cuyo ritmo es distinto a causa del cambio de tiempo gramatical. En ella el narrador no usa el yo personal sino el impersonal "se" ("se piensa"), obien el nosotros colectivo (llegaremos, solemos, lanzamos, nos reserva, etc.) a fin de subrayar que lo afirmado allí no es su juicio personal, sino un sentimiento difuso, compartido por todo el mundo. Pero, por más que se trate de una verdad generalmente conocida, ella está latente, inexpresa, de modoque el narrador tiene la función de dar una formulación a ese sentimiento común.

No debe dejarse de observar que este segmento no es ni una digresión ni una interpolación, las cuales truncarían en dos pedazos la línea fluida del cuento. Al contrario. Está firmemente enlazado con el segmento anterior y con el posterior mediante la figura retórica de la anadiplosis: el sintagma "la muerte", inicial 
de 5, repite, sinonímicamente, el sintagma final de 4: "al término de su existencia”; el “¿aún?” interrogativo, al principio de 7 , reitera el "jaún!" exclamativo, al final de 6.

Los dos términos diferenciales del tercer bloque, que es el mayor, son: a) el uso del presente narrativo en lugar del pasado (a diferencia del primer segmento); b) el retorno de la focalización interna, es decir, el suceso está relatado desde una perspectiva que se centra en la conciencia del moribundo; el narrador ve, siente y piensa lo que ve, siente y piensa el moribundo, ni más ni menos; $y$, a veces, la identificación es tan profunda que el narrador absorbe en su discurso el del personaje (por ejemplo, la serie de preguntas diseminadas a lo largo de la secuencia), recurriendo a los modos peculiares del discurso indirecto libre (o erlebte Rede). ${ }^{12}$

La novedad más importante de este tercer segmento es el cambio de tiempo gramatical, o sea, el uso del presente narrativo en lugar del pasado. ¿A qué se debe eso? Afirma Harald Weinrich que, por regla general, se cuenta una historia en pasado, pero, si debemos resumir su contenido, usamos el presente. Según Weinrich, la explicación está en el contexto: "el comentario que se hace de una obra literaria está en presente, $y$, por tanto, se expone en presente también el resumen de la obra comentada". ${ }^{13}$ En efecto, si se consulta cualquier historia o enciclopedia de la literatura, se observa que el argumento de las novelas está resumido en presente, precisamente como están enunciados en presente los juicios que el crítico emite sobre las mismas novelas. Weinrich llama a este texto en presente "texto comentativo". A nuestro parecer, dicha explicación, aunque exacta, es parcial. Nos inclinamos a creer que hay otra razón, igualmente fundada. El cuento, por lo general, se refiere a un suceso que se finge real y que ha transcurrido del todo en el momento en que se cuenta: por ese motivo se usa el tiempo pasado. El resumen del cuento, en cambio, se refiere no ya al suceso, sino al cuento del suceso; no ya a la realidad, sino a la transposición ficticia (literaria, plástica, o cinematográfica) de la realidad. Pero esa transposición vive en el libro, en el cuadro, en la pantalla: libre del vínculo del tiempo, y, por consiguiente, del pasado. Puede servir de ejemploel caso de la novela de Manuel Puig, El beso de la mujer araña: para pasar el rato, uno de los dos presos le cuenta al otro, de una forma a veces muy pormenorizada, algunas películas que ha visto, resumiéndolas siempre en tiempo presente, en tanto que usan regularmente los tiempos del pasado cuando los dos se cuentan sucesos reales de su propio pasado.

${ }^{12}$ Para una definición excelente del "discurso indirecto libre", con apropiados ejemplos, Angelo Marchese y Joaquín Forradellas, Diccionario de retorica, crttica y terminologia literaria (Barcelona: Editorial Ariel, 1986), 146, sin olvidar el ya clásico Fernando Lázaro Carreter, Diccionario de terminos filologicos, $3^{\mathrm{a}} \mathrm{ed}$. corregida (Madrid: Editorial Gredos, 1968), 236.

${ }^{13}$ Harald Weinrich, Tempus. Besprochene underzählte Welt, $2^{2}$ ed. (Stuttgart:Kohlkammer, 1971), cap. $\Pi$. 
Pero, como es evidente, el presente de tipo comentativo no tiene nada que ver con este relato de Quiroga, donde el narrador, en cierto momento de su narración, advierte la necesidad de cambiar de tiempo y de seguir narrando su historia en presente. Nos preguntamos, entonces: ¿cuáles son los casos en que se recurre, normal o preferiblemente, al presente en la narración? Hé aquí una pregunta a la cual quizá no puede darse todavía una respuesta exhaustiva. Lo único que podemos hacer ahora es bosquejar una tipología, aunque seaincompleta y provisional. Por ahora, alcanzamos a divisar los siguientes casos:

1) Resúmenes y guiones (ver arriba).

2) Textosirónicos que simulan un guión, como ocurre en las Moralités Légendaires de Jules Laforgue.

3) Descripciones (con más frecuencia que en los momentos propiamente narrativos): piénsese en las descripciones iniciales de ambiente o del marco geográfico en las novelas de Balzac o de Manzoni.

4) Secuencias de agitación narrativa, tendientes a comunicar una acción afanosa o tumultosa. En los ya citados episodios "Éxodo" de Roa Bastos y "Traslado de don Rodrigo al Lazareto" de Manzoni, el presente sirve para expresar agitación, igual que en ciertas secuencias cinematográficas afanosas y veloces crece el volumen del sonido, y se hace más rápido el ritmo de la banda sonora. Sin embargo, el presente puede también obedecer a una agogica opuesta: servir a un movimiento lento, tanto como a un movimiento presto.

5) Narración de sucesos que se centran en la inminencia de la muerte. Este quinto caso nos interesa ahora. Hay un cuento de Maupassant, titulado "Première neige", 14 cuyo protagonista, como en "El hombre muerto" vive en la espera de la muerte inminente. El relato es tri-segmentable. En la primera secuencia narrativa, ambientada en Cannes, a lo largo del Paseo de la Croisette, en el templado clima invernal de la Costa Azul, vemos a una joven señora que sale de una casa, y va a sentarse en un banco vacante frente al mar:

Son pale visage semble celui d'une morte. Elle tousse et porte à ses lères ses doigts transparents comme pour arrêter ces secousses qui l'epuisent ... Elle sait [...] qu'elle va mourir, qu'elle ne verra point le printemps, que, dans un an, le long de la même promenade, ces mêmes gens qui passent devant elle viendront encore respirer l'air tiède de ce doux pays ..." en tanto, que "elle ne sera plus. Toutes les choses de la vie continueront pour d'autres. Ce sera fini pour elle, fini pour toujours. Elle ne sera plus. Elle sourit tant qu'elle peut de ses poumons malades, les souffles parfumés des jardins. Et elle songe.

Toda la secuencia está relatada en tiempo presente. La segunda, en cambio, está en pasado, pues narra los recuerdos de la joven señora: era parisiense, y se había casado cuatro años antes con un gentilhombre de Normandía, pero en el helado castillo normando ella se aburría y extrañaba París, en tanto que su marido siempre iba de cacería. Ella se obstinaba en pedir

${ }^{14}$ Puede leerse en Boule de suif (París: Albin Michel, 1984), 225-235. 
un calorffero para templar los largos inviernos que tenía que transcurrir sola en el castillo, pero al maridoésta le pareća una petición absurda, casi una idea fija,

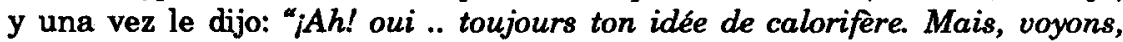
sacrebleu! tu n'as seulement pas eu un rhume depuis que tu es ici". Entonces ella comprendió que: “il fallait donc qu'elle fût malade, qu'elle toussât pour qu'il comprît qu'elle souffrait" Y una noche de invierno, sin hacer ruido, salio casi desnuda del castillo para caminar en el suelo cubierto de las primeras nieves, y volvió a la cama sólo cuando sintió que se moriría si se hubiese quedado un poco más a la intemperie. Tuvo una congestión pulmonar de la que sus pulmones, profundamente afectados, no se repusieron. Los médicos le aconsejaron transcurrir los inviernos en el Medidodía, a orillas del Mediterráneo, pero, también en este clima ideal ella sentía que ya le quedaba poco por vivir.

En la tercera secuencia de este cuento maupaussantiano volvemos a la situación inicial, narrada en el presente. La señora está sentada en el mismo banco, ha recorrido con la memoria los años de su desafortunado matrimonio, y “à présent, elle va mourir; elle le sait”. Pero está feliz, extrañamente, pues lee en un periódico un título que dice “La première neige à Paris", y ella ha logrado (si bien a precio de la vida) pasar el invierno en un clima mejor y, sobre todo, ver instalado por orden de los médicos un calefactor en el castillo, a despecho de su marido, incapaz de comprender sus necesidades.

Es un cuento, el de Maupassant, que casi empieza por el epílogo de la historia, y podria estructurarse de esta forma:

-Presente y previsión del fin inminente (A)

-Retrospección general (B)

-Presente y prevision del fin inminente (A').

También el relato de Quiroga principia por el fin, $y$, aunque no tiene un desarrollo tan geométrico se centra en el fin y, en el curso de la narración de este fin, venimos en conocimiento de algunos fragmentos esenciales del pasado En cuanto a los tiempos gramaticales, la estructura maupassantiana puede sintetizarse aún más: Presente (A) - Pasado (B) - Presente (A')

Es obvio que la retrospección de la segunda secuencia esté en pasado. Hay que explicar, en cambio, por qué Maupassant ha usado el presente en A y en A'. Los motivos pueden ser varios, si bien todos concurren al mismo efecto. Trataremos de exponer los que vemos con mayor claridad.

a) la oposición presente $><$ pasado realza mayormente el contraste entre A y A', por un lado (la señora, aunque enferma, está sola, feliz, lejos del marido desalmado), y B, por el otro (la señora, si bien todavía no ha enfermado, vive infeliz en el castillo del marido).

b) Maupassant emplea el presente para narrar un tiempo breve, en el cual los únicos sucesos pertenecen a la vida interior y para dilatarlo con la lente de aumento, en tanto que la secuencia B, relativa a un tiempo largo, es sumaria, hasta contraída, y tiene un marcado carácter de compendio. El presente acerca 
personaje y suceso al narrador y, por consiguiente, al lector, permitiendo seguirlos momento a momento, en cámara lenta, como si la escena se desenvolviese delante de él cinematográficamente y transcurriese en un tiempo que simula el de la vida. Como la vida se desenvuelve siempre en el presente, el presente gramatical permite captarla en su desenvolvimiento, en toma directa, no de forma retrospectiva. El presente gramatical comunica el tiempo vivido en este instante, en tanto que el pasado nos da un tiempo ya concluido y filtrado por la memoria.

c) En la narración en presente, el futuro no ha acontecido aún. En la narración en pasado, el futuro ha acontecido ya, aunque no nos ha sido revelado todavía. Suspenso e implicación emocional son mayores cuando la narración está en tiempo presente, que es precisamente lo que ocurre cuando una competición deportiva está retransmitida en directo en vez de en diferido. ${ }^{15} \mathrm{El}$ personaje de Maupassant "sabe que va a morir", pero no ha muerto todavía. De haberse empleado el pasado gramatical, su certidumbre hubiera sido formulada de la forma siguiente: "sabía que iba a morir", es decir, el tiempo de la narración se hubiera vuelto posterior a la muerte del personaje, lo cual, por cierto, habría disminuido la emoción angustiosa por esa muerte inminente, que ahora, en cambio, está vivida y vigilada agudamente, momento a momento, en su apremiante acoso.

Las razones que han aconsejado a Maupassant el uso del presente son esencialmente válidas también para el cuento de Quiroga, quien ha optado por este tiempo para la tercera y cuarta secuencia de su relato, dado que el presente es el tiempo de la vida y anima en medida mayor a ese lapso que media entre la imprevista certeza de la muerte inminente y la muerte misma: un tiempo intenso, diverso, excepcional, supremo, que también el narrador debe comunicar sirviéndose de un tiempo gramatical intenso y diverso, más adherente al hic et nunc vital: el presente, exactamente. Por otro lado, el uso del presente en lugar del pasado consiente al narrador una agilidad sintáctica y una economía morfológica indudablemente mayores. Si se hace el experimento de substituir en este tercer segmento el presente por el pasado, la morfología y la consecutio temporum se vuelven complejas y pesadas, en perjuicio de la propia soltura narrativa, del ritmo y de la velocidad del relato: el lugar de los pretéritos imperfecto, perfecto e indefinido es ocupado por el pluscuamperfecto, en tanto que se substituye el futuro por el potencial. El narrador hubiera tenido que emplear una serie de auxiliares que la elección del presente elimina automáticamente. Por último, Quiroga pretendió diferenciar bien los tiempos gramaticales para evitar que el lector confunda los dos pasados (el pasado del pasado y el pasado del presente) siendo tan numerosas las referencias al pasado, ya que el personaje no hace otra cosa que confrontar con él su presente.

${ }^{15}$ La oposicion psicologica que hay entre "transmision en directo" y "transmisión en diferido" es empleada muy finamente como analogía por Gérard Genette, op. cit., cap. "Voix". 
Nos queda todavía por señalar los dos elementos distintivos del cuarto, brevísimo segmento (25) de "El hombre muerto", que son: a) el fin de la historia continúa siendo narrado en presente; b) pero el suceso es visto ahora desde la perspectiva del caballo, única compañía animada del peón y testigo mudo de su muerte. La visual del caballo no es, empero, antropomórfica, sino meramente instintiva: para él el hombre es sólo un obstáculo entre el deseo y el objeto del deseo (las bananas) y, ahora que el animal se ha dado cuenta de que el hombre ya no constituye un impedimento, se decide a alcanzar la presa codiciada. El punto de vista, que ya no podía mantenerse en el hombre, quien, mientras tanto, ha muerto, tenía que trasladarse forzosamente al único testigo ocular de esa muerte solitaria, o sea, al caballo; tal desplazamiento está preparado en el penúltimo párrafo, cuando el punto de vista se aleja del moribundo como si fuera el espíritu vital que abandona el cuerpo y lo contempla desde afuera, la conciencia que, antes de disolverse, se desata del cuerpo desangrado: "Puede aún alejarse con la mente, si quiere: puede si quiere abandonar un instante su cuerpo y ver desde el tajamar ... y ... puede verse a sí mismo ..."(24).

\section{"EL HIJO"}

¿Qué puntos de contacto tiene este cuento ${ }^{16}$ con los dos que ya hemos examinado? En un mismo marco ambiental "misionero", en un mismo mediodía radiante, en medio de una naturaleza ambigua (ya partícipe, ya impasible), nos encontramos con un hombre en lucha con la muerte: un hombre anónimo, que en los dos primeros cuentos es alcanzado él mismo por la desgracia, en el tercero en la persona del ser más querido, o sea, del único hijo. Los tres casos relatan un accidente fatal (respectivamente: mordedura de una serpiente, herida con el machete, herida con el fusil), del cual el hombre (o su alter ego que es el único hijo) queda víctima. Los tres accidentes suceden durante el trabajo: la mordedura de la serpiente, mientras el hombre corta las cañas; la herida con el machete, mientras el hombre (su hijo, de apenas trece años no es todavía plenamente responsable) atiende a sus quehaceres en el taller de la casa. Los tres accidentes suceden por una leve imprudencia y en la soledad. Finalmente, las tres muertes ocurren por falta de auxilio: en el primer caso, nadie acude a socorrer al hombre; en el segundo, el hombre no está en condiciones de pedir ayuda; en el tercero, no se sabe si el hijo muere en el acto o por lento desangramiento, ya que el padre no le da importancia a la denotación, y sale en busca de él demasiado tarde.

Adviértase la relación especular que se forma entre las situaciones narradas en los dos últimos cuentos: en "El hombre muerto" el padre muere y los hijos, que no están lejos pero están a oscuras de lo que pasa, no acuden; en "El hijo"

\footnotetext{
${ }^{16}$ Vio la luz primero en La Nación (15-1-1928) bajo el título "El padre", y luego se recogí6
} bajo el título actual en "Más allá" (1935). 
el hijo muere, y el padre, que no está lejos pero se equivoca al tratar de explicarse el estampido, no acude. Todos ellos acudirán tardíamente, los hijos gritando “Piapiá!" (20 y 25) y el padre gritando “iChiquito! ... (38, 40, 42, 45). En los mismos cuentos la herida es causada por indispensables instrumentos de trabajoy de defensa como el machete y el fusil, que aquí, sin embargo, se vuelven proditoriamente contra sus dueños. $Y$, como última coincidencia, vemos que, tanto en "El hombre muerto" como en "El hijo", el accidente se produce mientras los protagonistas cruzan un alambrado. Es de suponer que en el caso de "El hijo" se trate de un alambrado aún más insidioso, oculto en la vegetación, tan frecuente en esas regiones donde el monte reconquista rápidamente las áreas de cultivo, cubriendo con su maleza los cercos de alambre de púa. Tales cercos, que se hacen sobre todo para proteger los cultivos contra el paso de caballos y reses, no constituyen una especial prohibición para los hombres o sea que, en la realidad referencial, cuando los dos protagonistas cruzan el alambrado, no cometen ninguna infracción. Sin embargo, ese acto puede percibirse, en una lectura arquetípica, como la infracción de una prohibición, a la que sigue, como necesario castigo, la muerte del culpable.

Para el análisis de "El hijo", hemos reservado dos lecturas separadas, aunque complementarias a la serie de las distintas secuencias que hemos identificado. En efecto, nos inclinamos a creer que las secuencias de un relato pueden examinarse desde dos perspectivas centralmente diferentes: a) desde un punto de vista esencialmente estático, que enfoca cada secuencia en sus peculiares aspectos de estructura y significado; b) desde un punto de vista esencialmente dinámico, que enfoca cada secuencia en las conexiones que presenta con las demás partes del texto y en su preciso aporte a la construcción y legibilidad del relato. ${ }^{17}$

Veamos primero la perspectiva $a$ )-

El segmento inicial, a pesar de los malos recuerdos del padre, está dominado por un sentimiento de felicidady de seguridad, irradiado por la propia naturaleza y sintetizado en la frase "el padre se siente feliz, tranquilo y seguro del porvenir" (19), con que se cierra la secuencia. Se podría hacer una ulterior subdivisión en tres partes: marco ambiental - inicio del episodio - (el hijo va de cacería) retrospección (se refieren los precedentes) que se inserta en la introspección (el padre acompaña con la imaginación al hijo en su camino). El punto de vista dominante es, por supuesto, el paterno, pero hay más. No debe olvidarse que todo el relato es introspectivo, o sea que es la dramática relación de lo que ocurre

\footnotetext{
${ }^{17}$ En "El hijo" distinguimos: I) primer segmento (párrafos l-19) que va desde el inicio hasta las palabras "tranquilo y seguro del porvenir"; II) segundo segmento (párrafos 20-43), y, precisamente, desde "en ese instante, no muy lejos, suena un estampido" hasta "Y el nuestro siente que las suyas se le escapan"; III) tercer segmento (párrafos 43-56, desde "cuando ve bruscamente ..." hasta "sonrie de felicidad"; IV cuarto segmento (párrafo 57 o último párrafo).
} 
en la conciencia del padre. Los sucesos que conciernen al hijo y ocurren fuera de la conciencia del padre no son más que dos: la salida del muchacho (párrafos 3-8) y el disparo (párrafo 20). Por otro lado, la exterioridad del estampido está aclaraday garantizada sólo por lo que se dirá en el úl timo segmento. Confrontando este cuento con los dos que hemos examinado anteriormente, vemos que el uso del presente gramatical, constante del principio al fin, confiere unidad temporal a todo el episodio, y nos ofrece una narración "en directo", provista de un ritmo más apremiante, más vivo, y de una morfología más ágil y veloz, de acuerdo con la norma quiroguiana de la economía verbal, que es también economía morfológica.

En el segundo segmento continúa el predominio del punto de vista paterno, excepto en ciertos enunciados en que se insinúa la voz del narrador omnisciente $(30,37-38)$. El sentimiento dominante es la ansiedad del padre en progresivo aumento. Se notará que el primer enunciado, “... suena un estampido" (20) proyecta una brusca sombra sobre ese sentirse "feliz, tranquilo y seguro del porvenir" (19) con que terminaba el segmento anterior. Por tanto, a la tranquilidad inicial sucede una inquietud creciente, pues el hijo no ha regresado para la hora señalada, y el disparo que ha escuchado dos horas antes ha adquirido un vago significado siniestro. A partir de “... mientras se descansa inmóvil" (27) hay un preciso presentimiento de la desgracia que se convierte luego en un crescendo de autosugestión, en lacerteza de la desgracia: "el espectro de la fatalidad" (30); "una gran desgracia..."(31); lolleva, fatal einexorablemente, al cadáver de su hijo" (33) [concordancia intertextual con "El hombre muerto": fría, fatal e ineludiblemente, va a morir (10)] ; "sólo la realidad fría, terrible y consumada: ha muerto su hijo al cruzar un ..." (34); "va el padre buscando a su hijo que acaba de morir" (39). El padre busca al hijo y lo invoca en un crescendo de terror: terror que llega a su punto culminante para acabar como una pesadilla (pero, aunque parece el término de una pesadilla, es el principio de la verdadera alucinación). Lainvocación logra su efecto, puesel hijo, si bien alucinatoriamente, aparece. Todo el crescendo del miedo, paralelo al paso del tiempo, hasta el desmayo del padre, está narrado con ritmo apremiante y trepidante aceleración, dignos del mejor Quiroga.

El sentimiento dominante en el tercer segmento es el de una felicidad recuperada. El padre, terminada la pesadilla, con una profunda sensación de alivio, vuelve a sonreír de felicidad. El sintagma "sonríe de felicidad" (56) reanuda, aunque sólo sea un instante, la isotopía propia del segmento inicial: "se siente satisfecha de si" (1); "abre también su corazón" (2); "feliz con la alegría de su pequeño" (8); “y el padre sonríe" (13); “el padre se siente feliz, tranquilo y seguro del porvenir" (19).

Este tercer segmento, compacto y homogéneo, está construido en decidido contraste con el anterior: si el anterior es una pesadilla, éste es realidad; si el anterior es realidad, éste es un espejismo. Continúa obviamente el predominio del punto de vista paterno, con la posible excepción del período "A un chico de 
trece años bástale ver ...” (44), que no parece ser un pensamiento que el personaje pueda concebir en ese momento: parece, en cambio, una verdad general que enuncia el narrador invisible.

El cuarto segmento está formado por el último párrafo, y está separado del cuerpo textual por una raya, que designa un cambio brusco de dirección narrativa. Por lo pronto, la focalización es cero: aquí interviene el narrador invisible (e impasible), que, con estilo informativo, como si redactara una aclaración final, nos hace saber que la recuperada felicidad del padre es sólo una alucinación, y que el hijo ha muerto realmente cuando el padre ha oído el estampido sin darle importancia. La focalización ha cambiado radicalmente, puesto que el narrador sólo se preocupa por desmentir la perspectiva anterior, advirtiéndose que no es verdad lo que el padre, víctima de una alucinación, cree ver: el padre no ha encontrado al hijo, y éste ha muerto poco después de salir de la casa, al cruzar el alambrado, herido por una descarga accidental de su fusil. La ubicuidad es parte integrante de la omnisciencia del narrador pues éste sabe que el padre, aunque cree volver en compañía de su hijo, va solo y que en una zona del monte, "tras él, al pie de un poste y con las piernas en alto, enredadas en el alambre de púa, su hijo bienamado yace al sol, muerto desde las diez de la mañana"(57). Es interesante observar que, al principio del párrafo, Quiroga se sirve de la anadiplosis, aunque no para corroborar la información del enunciado que reitera, sino para desmentirla: la simple interpolación del adjetivo "alucinada" en el sintagma que se repite le quita al compasivo lector toda esperanza de que aquella felicidad no sea una mera alucinación del personaje.

Veamos ahora la perspectiva $b$ ) -

La secuencia inicial nos ofrece los datos esenciales para la legibilidad del texto. El padre, viudo, está muy apegado a su único hijo, de cuya educación ha debido hacerse él solo responsable. Lo ha acostumbrado a vivir en medio de los peligros, pues cree firmemente que sólo afrontándolos consigue el hombre defenderse de ellos. Sin embargo, este principio pedagógico, que ha llevado escrupulosamente a la práctica, le da remordimientos y miedos, siendo tan fácil que un chico cometa un error y acabe por ser víctima de una educación tan dura. El padre, postrado por las adversidades, atormentado por sus contradicciones, sufre de alucinaciones: ha visto al fantasma de su esposa difunta (lo dice de una forma muy vaga: "Ha visto, concretados en dolorosísima ilusión, recuerdos de una felicidad que no debía surgir más de la nada en que se recluyó" 18 ); ha visto una vez a su hijo "rodar envuelto en sangre cuando el chico percutía en la morsa del taller una bala de parabellum, siendo así que lo que hacía era limar la hebilla de su cinturón de caza" (ibid.)

El padre, pues, vacila entre los dos estados de ánimo opuestos: a veces prevalece su optimismo pedagógico; otras veces, su miedo de hombre aprensivo que siempre teme una desgracia. Sin embargo, el día en que tiene lugar la historia, el padre, casi por efecto del sol radiante y de la vitalidad de la naturaleza, está optimista. Entre los elementos de ese primer núcleo, el 
narrador ha anticipado un dato esencial para el desarrollo ulterior del cuento, o sea que el padre sufre de alucinaciones (17). Es un dato cuyo relieve estará puesto en claro por las secuencias sucesivas y que, desde ahora, prepara la comprensión de las mismas. Se trata, por tanto, de un elemento conectivo, concadenante, indispensable para lainterpretación del texto. Algunos semiólogos han propuesto llamar "anáforas" a tales procedimientos, entendiendo por este término no la conocida figura retórica, sino, en sentido narratológico, todo envío semántico a otra parte del mismo texto $u$ a otro texto. ${ }^{18}$

El primer dato de la segunda secuencia es "un estampido" (20) que suena no muy lejos: su colocación, luego que el narrador ha subrayado la felicidad del padre, "seguro del porvenir" (19), confiere a este signo un sentido siniestro. Es verdad que el personaje, al principio, no le hace mucho caso, pero el signo actúa subterráneamente para salir a flor de tierra más adelante poniendo al descubierto su contenido funesto. Estamos otra vez en presencia de una anáfora que pone al lector frente a una disyuntiva: 1) creer que ese disparo es real; 2) creer que ese disparo es alucinatorio (en efecto, la alucinación que el padre había tenido en el taller nos hace sopechar que sufre aquí una recaída en su estado morboso). A su vez, la primera alternativa presenta dos posibilidades: a) el disparo ha herido al hijo; b) el hijo ha disparado contra un animal.
1. Realidad
a. Disparo $>>$ Hijo
2. Alucinación
b Disparo $\gg \gg$ Animales

Adviértase que 2 y 1 b se equiparan, pues en los dos casos el hijo queda incólume: lo temible es sólo la. Toda la secuencia nos sume en la incertidumbre acerca de la muerte del chico. Por un lado, hay elementos que nos hacen pensar en un infortunio: el chico, que casi siempre vuelve a casa puntual, ha prometido volver para la hora del almuerzo, pero la hora ha pasado y él no ha vuelto; después del primer disparo no se han oído otros; en todas partes hay alambrados: el padre no había reparado en este riesgo, que sólo ahora se presenta a sus ojos en toda su gravedad. Otros signos, al contrario, inducen a pensar que no ha pasado nada: véanse las consideraciones del padre en discurso indirecto libre (“iEs tan fácil, tan fácil perder la noción de la hora dentro del monte ...!”, 27) y las del narrador ("Distracción, olvido, demora fortuita ..." 30); "un pobre hombre alucinado a la más atroz pesadilla ...”, 43). El lector, si por un lado se deja implicar por la progresiva convicción del padre de que al hijo le ha ocurrido una

${ }_{18}$ Julia Kristeva, Sèméiotiké. Recherches pour sémanalyse (París: Seuil, 1969), 90-83; L. Lonzi, "Anaphore et récit", Communications, 16 (1970); Lisa Block de Behar, "La recurrencia anaforica de Juan Rulfo", Texto Critico 5 (1976). 
desgracia, por el otro mantiene cierto desprendimiento crítico, y sólo ahora empieza a atribuir valor a esa información básica de la primera secuencia, esto es, que el padre sufre alucinaciones: en efecto, podría también tratarse de un caso de auto-sugestión que se ha producido sobre la base de indicios insignificantes.

Al comienzo de la tercera secuencia, "cuando [el padre] ve bruscamente desembocar de un pique lateral a su hijo" (43), inmediatamente el lector deja de vacilar y concluye que se ha tratado de un fenómeno de auto-sugestión, por cierto comprensible, pero sin duda de proporciones patológicas: concluye, por tanto, que el chico no ha muerto y regresa a casa al lado de su padre, quien, preocupado por la demora, ha ido a su encuentro. El círculo se cierra: después de un banal percance y un gran susto, se vuelve a la situación inicial, es decir, a la normalidad.

Los lectores no sospechan (salvo los muy duchos en trucos narrativos) que el breve párrafo final, que constituye la cuarta y última secuencia, desmiente lo anterior mediante un repentino cambio de punto de vista. El tránsito es brusco, y no sabríamos decidir si la anadiplosis atenúa o refuerza esa brusquedad. En la secuencia precedente se pasaba de la incertidumbre a la certeza; ahora, en cambio, se pasa de una certeza a la certeza opuesta, que restituye validez a la primera alternativa de la segunda secuencia: el disparo es real y ha matado al hijo. El padre está alucinado, no en la segunda secuencia, sino en la tercera, cuyo desenlace feliz el lector ha aceptado con prisa excesiva.

El cuento, considerado en sus cuatro partes, desarrolla la anáfora siniestramente premonitoria del primer segmento:

lo ha visto una vez rodar envuelto en sangre cuando el chico percutía en la morsa del taller una bala de parabellum, siendo asi que lo que hacía era limar la hebilla de su cinturón de caza (18).

Sólo en el último segmento nos damos cuenta de que tal premonición no estaba equivocada. El presagio se cumple, al igual que en los cuentos folklóricos donde la profecía se cumple siempre, aunque cada uno de los episodios parezca negarla, aunque un primer falso desenlace pueda parecer feliz. Lo mismo pasa en "El hijo", donde, a través de un procedimiento de contrastes y retornos, bruscos y chocantes, se llega a ver cumplido ese presagio que por dos veces el relato ha propuesto como falso:

ler. segmento: el presagio es falso: "Lo ha visto una vez rodar envuelto en sangre..." (18), pero se trata claramente de una alucinación.

20. segmento: el presagio puede ser vertdico.

3er. segmento: el presagio era falso.

4o. segmento: el presagio era verídico.

Concluiremos afirmando lo siguiente. Distinguimos entre escritor y narrador, y nuestra distinción, esta vez, no es semiológica, sino el reconocimiento 
de una vocación, de una especial aptitud. Es posible tener ambas capacidades al mismo alto nivel. Hay, sin embargo, excelentes escritores que no son igualmente excelentes como narradores, y, viceversa, narradores admirables que son menos admirables como escritores. Quiroga me parece pertenecer a esta segunda categoría: el estiloes pobre, genérico a veces, aunque nunca carece de una elemental eficacia alusiva; el corte y el ritmo narrativos son, en cambio, magistrales, por lo menos en algunos de sus mejores cuentos. Creemos que Borges, al condenar en términos tan drásticos la literatura de Quiroga, ${ }^{19}$ olvidó tener en cuenta esta doble naturaleza de las dotes del prosista.

\footnotetext{
${ }^{19}$ Fernando Sorrentino, Siete conversaciones con Jorge Luis Borges (Buenos Aires: Casa
} Pardo, 1973), 76-77 